\title{
A Research on Environmental Protection Public Service of Farming and Stockbreeding Areas in Inner Mongolia Autonomous Region
}

\author{
Jia-Zhi CHEN ${ }^{1, a,{ }^{*}}$, Yue-Wen GAN ${ }^{1, b}$ \\ ${ }^{1}$ College of Public Administration, Inner Mongolia Normal University, 010022, P.R.China \\ aseraphcjz@126.com, bganyw@imnu.edu.cn \\ ${ }^{*}$ Corresponding author
}

Keywords: Public service, Service platform, Needs of farmers and herdsmen, Nonprofit organizations, Information services.

\begin{abstract}
The paper invoked Public Service System Model which centers on "service triangle". By taking common people and national civil servants in the farming and stockbreeding areas (FSA) in Inner Mongolia Autonomous Region as the research objects, with the major research methods of literature study and questionnaires, this paper investigated and analyzed the differences of those two groups on their basic needs towards public service and their satisfaction with the "infrastructure construction and environmental protection platform", thereby researched the relationship between "service platform" and "needs of farmers and herdsmen" in the "infrastructure construction and environmental protection service system" in the FSA in Inner Mongolia. The results showed that, compared with the national civil servants, the common people in the FSA in Inner Mongolia had lower basic need towards the "public service of infrastructure construction and environmental protection" and lower satisfaction with the "service platform". Based on the analysis of the research results, and in reference to successful experiences of domestic and foreign public services, this paper recommended to innovate and develop nonprofit organizations as well as to create innovative electronic information system of public service in the FSA in Inner Mongolia, in order to effectively improve the service capability of the public service platform of environmental protection in the FSA in Inner Mongolia, and to enhance the public governance capability of local governments at the grassroots level in Inner Mongolia, which could lay a solid foundation for the construction of service-oriented government.
\end{abstract}

Establishment of the public service system model based on "service triangle" in the farming and stockbreeding areas in Inner Mongolia Autonomous Region

Definition of "public service" has been quite controversial over years, and has never formed consensus in the relative complete public service system in European countries. Many representative domestic and foreign scholars, including John Maynard Keynes, Paul Anthony Samuelson, Elinor Ostrom, David Osborne and Ted Gaebler, as well as the Denhardt couple (Denhardt, Robert B. and Denhardt, Janet V), have put forward the concept of public service from different levels and perspectives based on the actual situation in China. In 1954, Samuelson published the article - "The Pure Theory of Public Expenditure" - in The Review of Economics and Statistics. He deduced and explained the term "public service" from the perspective of "public goods", which is "each individual's consumption of such a good leads to no subtraction from any other's consumption of that good". James McGill Buchanan raised the opinion that "public service is or not only is the provision of public goods which is goods or services decided and provided by any group or social organization for any reason". Osborne and Gaebler, on the other hand, argues that "government should be steering rather than rowing" [1]. Denhardt couple held the opinion that "the increasingly important role of public officials is to provide public service, that is to help the citizens to express their common interests and needs and then to meet those needs, rather than trying to control or steer society towards a new direction, as well as to serve basic responsibilities for public interest"[2]. Generally speaking, public service can be defined in the following five ways: 
first, the characteristics of public goods; second, the content and scope of public service functions; third, the needs of objects and ways to realize their value; fourth, the distinction between public and private interests; fifth, the objects and content of the service provided [3]. "The Twelfth Five-Year Plan for National System of Basic Public Services of the People's Republic of China" (hereinafter referred to as "the plan"), which was issued by the State Council of People's Republic of China in 2012, followed the fifth way in defining "public service". It expounded the institutional arrangements of the national basic public services, and clarified the basic scope, standards and priorities of public service system. According to the plan, "basic public services" was defined as "public services which are built on the basis of certain social consensus, mainly provided by the government, compatible with levels and stages of the economic and social development, and designed to guarantee the basic needs of all citizens towards their survival and development." The citizens have been entitled to public service while the government is responsible for the provision of basic public services. Scope of basic public services usually include public services, which "guaranteed the basic livelihood needs, in fields of education, employment, social security, health care, family planning, housing guarantee system, culture, sports, etc. In a broad sense, it also covers public services which are closely related to people's living environment, including transportation, communications, communal facilities and environmental protection, and which are about the safety needs, including fields of public safety, consumer safety, national security and other fields."

"Management" and "service" are the two keywords related to public services. The key to providing better public service is the organic combination of "management" and "service". When discussing the relationship between "service" and "management" from the perspective of the theory of market economics, it's easy to find that there are simple links between "business" and "customer" in the "non-competitive and non-exclusive" markets which provide pure public goods or quasi-public goods. Here, "business" can be understood as a public service provider, and the "customer" as a public service recipient or purchaser. Then according to "polycentric governance"[4]theory, it relates to issues which can be summarized as issues of internal relationship within the public service industry, including financing, use management, collaborative production, system construction, infrastructure construction and urban development and so on.

When exploring the internal relationship of the public service industry in theory, we can target on the service management concepts, namely, how to shift the "customer- centric" concept as one critical and eternal part in management thinking. Karl Albrecht and Ron Zemke, two famous American management experts, proposed the "triangle model" [5] of service management in The New Economy published in 1985. Then, they clarified the definition of "service triangle model" in their co-authored book - Service America in the New Economy. When fitting and extending this theory into various service fields, it's obvious that the "service triangle" has built up a complete set of bridges which connected public administration with business management. Its significance is that we can bring the value of citizens to the government's stage center to realize the transformation from producers' society to customers' society. Its significance also lies in the comprehension of "holistic" view. Based on the equalization, diversification and responsibilization of the public service with the core of service objects' needs, it established a seamless system combined with "public service policy system", "service platform system" and "human resource system". Meanwhile, this system can not only be used as the framework foundation of certain public service sector, but also be extended to other public service sectors till it covers the whole public service domain. That is to say, it realized the formation of a complete service system within sectors or fields, the link between sectors and between fields, as well as the macro-system with complete public service. The following diagram can be summarized when practicing this system in the public service system of the farming and stockbreeding areas (hereinafter referred to as FSA) in Inner Mongolia Autonomous Region. This complete diagram of public services of FSA in Inner Mongolia is centered and based on the "service triangle" and is divided into three levels. The three levels are respectively as follows. The first level - "service triangle" - is the core of the system functioning, which is divided into four subsystems, namely "farmers demand subsystem", "service 
platform subsystems", "public policy subsystem " and "human resources subsystem". The second level sets respective service operation mechanism structures for the four subsystems of the "service triangle". It is derived from the four subsystems of the first level and equipped with main mechanism construction from four aspects for each subsystem. The third level is the specific structure of the public service system of FSA, which can be divided into eight systems and is the external expression of the first and the second levels.

\section{Analysis of the service system of infrastructure and environmental protection of FSA in Inner Mongolia}

Based on the above theory, this paper focuses on the relationship between "service platform" and "farmers' needs" in the "service system of infrastructure and environmental protection". By taking common people, who are the recipients of the service platform, and national civil servants, who are the providers of service platform, in the farming and stockbreeding areas (FSA) in Inner Mongolia Autonomous Region as the research objects, this paper investigated and analyzed the differences of those two groups on their basic needs towards public service and their satisfaction with the infrastructure construction and environmental protection platform". The specific investigated districts include: Wudan Town of Wengniute Banner in Chifeng City, Tumuji Village of Xing'an League, Limin Village of Dayushu Town in Kailu County of Tongliao City, Haibowan District and Hainan District of Wuhai City, Baori Hushu Village of Zhonghexi Town in Dalad Banner of Ordos City, Guyang County of Baotou City, Bailingmiao Town of Damao Banner in Baotou City, Jingping Village of West Naobao Back Street in Baotou City, Jia'erba Village of Baotou City, Shamujia Village of Baotou City, and the Third Brigade of Rangeland in E'er Guna City (county-level city) of Hulunbuir City (prefecture-level city).

A large quantity of first-hand materials were collected through visits, on-the-spot investigation and questionnaires. With statistics and analysis of the data from over 600 valid questionnaires, and with basic public services of infrastructure construction and environmental protection as core research objects, the result reveals the current situation and demand of the public service in FSA in Inner Mongolia, as well as the cognitive difference towards current situation and demand of public service from different groups, especially the cognitive difference between common people and national civil servants of FSA in Inner Mongolia. The main differences are reflected in the following aspects:

\section{Compared with the national civil servants, the common people in the FSA in Inner Mongolia had lower need towards the "public service of environmental protection"}

According to the statistics results of the research group (the same with the following data), the average value of the basic needs of national public officials towards basic public service in FSA in Inner Mongolia is 7.1. The needs for the basic public service which are equal or greater than 7.1 are distributed in the following fields: medical services and security, income raise, guidance of agricultural production and stockbreeding, children's education, rural cooperative credit, environmental protection, water conservancy facilities construction of farmland and rangeland, road construction of villages and rangeland, and construction of drinking water facilities. The value of the basic needs towards medical services and construction of drinking water facilities are the highest among all the statistics, which were all 10 points. The value of the needs for Environmental protection is 7.8 , which is greater than the average needs for basic public services.

The statistical results showed that the average value of the basic needs of common people towards basic public service in FSA in Inner Mongolia is 7.0. The needs for the basic public service which are equal or greater than 7.0 are distributed in the following fields: medical services and security, income raise, children's education, pension system, social security of minimum living standard, water conservancy facilities construction of farmland and rangeland, social security, road construction of villages and rangeland, legal assistance and construction of drinking water facilities. 
The value of the basic needs towards medical services and security is the highest among all the statistics, which is 9.7 points. The value of the needs for Environmental protection is 5.7, which is obviously lower than the average needs for basic public services. It can be concluded that compared with the national civil servants, the common people in the FSA in Inner Mongolia had lower need towards the "public service of environmental protection".

Compared with the national civil servants, the common people in the FSA in Inner Mongolia had lower satisfaction with the local "service platform" of the service system of inf rastructure construction and environmental protection

Among 16 of all the indicators of the "service platform" in the service system of infrastructure construction and environmental protection, 32\% of the common people in the FSA in Inner Mongolia evaluated service platform as "very satisfied" or "quite satisfied", while majority of them hold neutral or negative opinion towards the "service platform" in the service system of infrastructure construction and environmental protection. Among 16 of all the indicators of the "service platform" in the service system of infrastructure construction and environmental protection, $51 \%$ of the national civil servant in the FSA in Inner Mongolia evaluated service platform as "very satisfied" or "quite satisfied", which shows majority of them hold positive opinion towards the "service platform" in the service system of infrastructure construction and environmental protection. Generally speaking, compared with the national civil servants, the common people in the FSA in Inner Mongolia had lower satisfaction with the local "service platform" of the service system of infrastructure construction and environmental protection.

\section{Both common people and national civil servants in the FSA in Inner Mongolia had lower satisfaction with inf rastructure of environmental protection}

Among the 16 indicators of the "service platform" of the service system of infrastructure construction and environmental protection, 5 of them have relatively close correlation with environmental protection infrastructure, which are "garbage innocuous disposal", "industrial pollution control", "pollution control of livestock breeding", "non-point source pollution control of agricultural and livestock breeding industries", and "soil pollution control in the FSA". 20\% of the common people in the FSA in Inner Mongolia evaluated the above 5 services as "very satisfied" or "quite satisfied", which is lower than the $32 \%$ overall evaluation value towards other 16 indicators. $30 \%$ of the national civil servants in the FSA in Inner Mongolia evaluated the above 5 services as "very satisfied" or "quite satisfied", which is lower than the $51 \%$ overall evaluation value towards other 16 indicators. It is believed that as for the environmental protection infrastructure, both the common people and the national civil servants have lower satisfaction which is below average, of which the value of common people is lower than that of the national civil servants.

\section{Both common people and national civil servants in the FSA in Inner Mongolia had lower satisfaction with the advocacy and education efforts of local environmental protection}

Among the 16 indicators of the "service platform" of the service system of infrastructure construction and environmental protection, 1 of them is directly related with the advocacy of environmental protection awareness, which is the "advocacy and education efforts of local environmental protection". $12.5 \%$ of the common people in the FSA in Inner Mongolia evaluated this indicator as "very satisfied" or "quite satisfied". 34\% of the national civil servants in the FSA in Inner Mongolia evaluated this indicator as "very satisfied" or "quite satisfied". As for the advocacy and education efforts of local environmental protection, both the common people and the national civil servants have lower satisfaction which is below average, of which the value of common people is lower than that of the national civil servants.

In summary, the satisfaction values with the 6 indicators (which are closely correlated with environmental protection infrastructure and the advocacy of environmental protection awareness) 
are all lower than the overall evaluation values of the 16 indicators of the "service platform". Meanwhile, in the aspect of environmental protection, the common people are less satisfied compared with the national civil servants in the FSA in Inner Mongolia.

\section{Innovation of service platform and enhancement of the basic public services of environmental protection}

The guiding spirit of the "China Dream" elaborated of by Xi Jinping, the general secretary of the People's Republic of China, and the guiding documents, including Report to the Eighteenth National Congress of the CPC, The China National 12th Five-Year Plan for Environmental Protection, The China National Development Strategy and Contemporary Action Plan of Revolving Economy, The China National 12th Five-Year Plan for Energy Efficiency and Environmental Industry, The China National 12th Five-Year Plan on National Urban Wastewater Treatment and Recycling Facilities Construction Program, have provided strategic guidance to the public services development of infrastructure construction and environmental protection. Under the current situation of increasingly obvious environmental protection problems and serious environmental pollution, Inner Mongolia Autonomous Region should improve the common people's satisfaction with basic public services of environmental protection through improving the public service of environmental protection, and further enhancing the environmental protection awareness of the local people by deepen the advocacy and education efforts of local environmental protection. By drawing on the successful experience of domestic and foreign public services, the author recommended to improve the basic public service of environmental protection in the FSA in Inner Mongolia through the innovation of service platform.

\section{Development of nonprofit organizations}

"Nonprofit organizations" can remedy the "government failure" and "market failure" in all fields of public services. Since the 1980s, the U.S. nonprofit organizations showed overall growth trend in both quantity and scale. Up to March 2012, nearly one million public charities and 100 thousand private foundations as well as over 400 thousand other nonprofit organizations of other types had registered in IRS (Internal Reserve Service) [6], which covered 12 fields, including culture and entertainment, educational research, health, social services, environmental protection, development and housing, legal advocacy and education, charity agency and voluntary services, international activities, religions, business and professional associations, etc. Professor Salamon proved through empirical studies that "nonprofit organizations have become a significant economic force in contemporary Western countries, which play a huge role in the provision of public service.

In Western Europe and other developed countries, about $7 \%$ of the non-agricultural labor force was accounted by nonprofit organizations, which was far beyond that of Latin America and Eastern Europe (the figure was only $2.2 \%$ in Latin America and only 1.1\% in Middle and Eastern Europe). Nonprofit organizations play a leading role in three public service fields, including education, health care and social services.[7].

Through the research of the US public service fields, it is believed that foreign NGO and other nonprofit organizations have played crucial roles in the field of environmental protection and other public services. Only in Los Angeles County, California, there are 56 NGOs specifically aimed at the basic public service of "garbage innocuous disposal" in environmental protection field, which showed the highly developed nonprofit organizations in US. In terms of the development of China's NGO, China should actively carry out the improvements in policy, law and awareness, and to fill the gap and to repair the gap between "service platform" and "needs of farmers and herdsmen" by vigorously developing nonprofit organizations and NGOs. In the field of environmental protection in China, there are also a large number of various non-governmental organizations which are quite active. These NGOs mainly focused on the following areas: the popularization, education and advocacy of environmental protection awareness, promoting and facilitating public participation in 
environmental protection activities; funding for environmental protection activities; project activities related to natural resources and environmental protection; research, development and popularization activities of environmental conservation science and technology; production, marketing and other joint activities of environmental protection industry related to environmental protection products; assistance activities concerning environmental pollution victims; international exchange activities for environmental protection.

\section{Establishment and spread of innovative public electronic information service network}

In recent years, the Chinese government continuously innovate the supply model of public services. The advent of $4 \mathrm{G}$ mobile Internet era generated huge change in people's habits of surfing and accessing information. Cell phone use greatly facilitates the handling of the many inquiries and business services. For the government, the construction of electronic platform for government affairs through mobile smart-phones is an important innovation. For example, the information push platform of "Beijing services you", which was launched by the Beijing municipal government, covers consulting, interactive activities, business handling, inquiries and other functions. Alike APP platforms are also launched in Shanghai, Ningbo, Jinan and other cities in China. As for many foreign countries, such as Sweden, the State Administration of Taxation, the General Administration of Customs, and many local authorities are already using text messaging to communicate with the public. Among all 7 million Swedish taxpayers, more than 90,000 conduct annual tax procedures with mobile phone completely.

Therefore, how the government provides the public with more practical and more convenient service through mobile internet is a new proposition and challenge to the government's public service capacity. At present, strengthening the advocacy of environmental protection through the electronic information network needs the whole government to carry forward in internet era. Electronic information networks, such as weichat, microblog and other important communication platforms, can be bridges between the government and the public. In the era of "big data", cloud computing technology, e-government systems of the government, enterprise management information system, and even cloud system of electronic information for universal public service which represents the future development trend, can be the important platforms and bearers of the advocacy and education functions of the government. They can become publishers as well as recipients of information and achieve information interflow between different parties. All-digital business can be realized through one-stop processing of the information network platform. With the development of "broadband China" in China, to achieve the advocacy purpose through information communication tools with technology is an important way for the innovation of Chinese government in public service means.

\section{References}

[1] David Osborne, Ted Gaebler, Reinventing Government: How the Entrepreneurial Spirit is Transforming the Public, Shanghai Translation Publishing House, Shang Hai, 2006, pp. 5-6.

[2] Janet V. Denhardt, Robert B. Denhart, The New Public Service: Serving, not Steering, China Renmin University Press Co., LTD, Bei Jing, 2004, pp. 43-141.

[3] Fang Xi, Research on new rural public service system in contemporary China, first ed., China Social Science Press, Bei Jing, 2010, pp.20-21.

[4] Elinor Ostrom, Governing the Commons: the Evolution of Institutions for Collective Action, first ed., Shanghai Translation Publishing House, Shang Hai, 2012.

[5] Karl Albrecht, Governing the Commons: the Evolution of Institutions for Collective Action, China Social Science Press, Bei Jing, 2004. 
[6] Ding Jingjing, The Non-Profit Organization and the development of its legal regulation In USA, J. Foreign Theoretical Trends. 7 (2013) 97-104.

[7] Wen Yanping, Research on social and economic effort of Non-Profit Organization, J. Reformation \& Strategy. 4 (2007) 49-50. 